\title{
Propiedades de textura de masa y pan dulce tipo "concha" fortificados con proteínas de suero de leche
}

\author{
Propriedades de textura de massa e de pão doce tipo concha fortificados com proteínas do soro de leite
}

\author{
Norma GÜEMES VERA ${ }^{1 \star}$, Alfonso TOTOSAUS ${ }^{2}$, \\ Juan Francisco HERNANDEZ ${ }^{1}$, Sergio SOTO ${ }^{1}$, Elia Nora Aquino BOLAÑOS ${ }^{1}$
}

\begin{abstract}
Resumen
La fortificación de alimentos es importante debido a una creciente población en estado de malnutrición, por las sequías provocadas a nivel mundial y por personas de bajos recursos económicos. La adición de proteínas puede causar problemas tecnológicos. Por ello, el objetivo de este trabajo fue determinar el efecto de la adición de proteínas de lactosuero a pan dulce tipo "concha" sobre las propiedades químicas y de texturas de las masas y panes. Se planteó un experimento con diferentes concentraciones de suero comercial y precipitado por calor, se evaluó la adhesividad y el análisis del perfil de textura en masa y panes. Los resultados indicaron que el testigo presentó menor contenido de proteína (17.2 $\pm 0.01 \%)$ con respecto a los panes con $10 \%$ (19.8 \pm 0.01$)$ y $15 \%(22.9 \pm 0.03)$ de suero comercial y precipitados por calor, el contenido de grasa fue similar en el testigo $(7.01 \pm 0.02)$ y en los panes con suero comercial $(7.29 \pm 0.04 \%)$ y precipitado por calor $(7.37 \pm 0.01)$, el mayor trabajo de adhesión se presentó al $10 \%$ de suero comercial, mientras que los tratamientos a base de suero tuvieron valores intermedios. La firmeza fue mayor $(\mathrm{p}<0.05)$ en las muestras con proteína de suero comercial, pero menos cohesiva que las fortificadas con suero precipitado por calor. La firmeza del pan mejoró por la presencia de suero lácteo comercial que con el suero precipitado por calor, sin detectar diferencia significativa $(\mathrm{p}>0.05)$ entre los porcentajes de suero. Existe un efecto del tipo y concentración de suero en la adhesividad de las masas. Respecto a la textura de los panes, el suero precipitado por calor tuvo características aceptables en comparación con el suero comercial. Palabras-clave: pan; panificación; fortificación de alimentos; textura; adhesividad.
\end{abstract}

\section{Resumo}

A fortificação de alimentos é importante devido a uma população crescente em estado de má nutrição. A adição de proteínas pode causar problemas tecnológicos. Por essa razão, o objetivo deste trabalho foi determinar o efeito da adição de soro de leite a formulações de pães tipo concha nas propriedades químicas e na textura das massas. Foram utilizadas diferentes concentrações de um soro comercial e de outro soro obtido por processo de precipitação por calor. Foi avaliado o perfil de textura da massa e dos pães. Os resultados indicaram que o controle apresentou maior adesividade enquanto o soro precipitado produziu amostras com valores intermediários. A dureza foi maior ( $\mathrm{p}<0,05)$ em amostras com soro comercial, porém com menor coesividade que as fortificadas com soro precipitado pelo calor. Não houve variação significativa $(\mathrm{p}>0,05)$ na firmeza, quando utilizadas diferentes porcentagens dos dois soros testados. Há correlação entre a concentração de soro e a adesividade das massas.

Palavras-chave: pão; fortificacion; fortificação de alimentos; textura; adesividade.

\section{Introducción}

La fortificación de los alimentos ha sido una práctica común en las sociedades actuales, buscando ofrecer alimentos más nutritivos sobre todo a sectores de la población con problemas de desnutrición Güemes et al. (2008). Los productos de panificación, debido a sus características de vida de anaquel (baja $\mathrm{a}_{\mathrm{w}}$, por lo que es menos susceptible a crecimiento microbiano), su bajo costo y formulación, son productos que pueden ser enriquecidos al adicionar otras proteínas, como concentrados o aislados proteicos de diversas leguminosas. Existen varios reportes referentes a modificar el contenido proteico de masas y panes sin alterar las características del producto final. Taha, Attia y Saeta (1982) utilizaron cinco fuentes diferentes de proteínas en el enriquecimiento de pan blanco, añadiendo concentrados de proteína de semillas de girasol, soya, harina de lupino, arroz y pescado a niveles del 5 y $10 \%$, encontrando que el contenido de proteína se elevó de 16 a $60 \%$, dependiendo del concentrado utilizado, pero utilizar un nivel del 5\% de adición de los concentrados favorece el enriquecimiento del pan blanco sin afectar características de color, aroma, sabor o textura. Por otra parte, el uso de concentrados y aislados de harina de lupino sin grasa mezclados con harina de trigo demostraron que la proteína de esta semilla mejoró la estructura proteica de las masas Güemes, Arciniega y Davila (2004). Del mismo modo, aislados de ajonjolí pueden ser añadidos a panes de harina de trigo incrementando el nivel de proteína en

Recebido para publicação em 3/7/2007

Aceito para publicação em 28/10/2008 (002635)

${ }^{1}$ Centro de Investigación en Ciencia y Tecnología de Alimentos, Instituto de Ciencias Agropecuarias, Universidad Autónoma del Estado de Hidalgo, Av. Universidad Km 1, Tulancingo 43000, Hidalgo, México, E-mail: njgv2002@yahoo.com.mx

${ }^{2}$ Laboratorio de Alimentos, Tecnológico de Estudios Superiores de Ecatepec. Av. Tecnológico y Av. Central s/n, Ecatepec 55210, Estado de México, México,

E-mail: totosaus@att.net.mx

${ }^{*}$ A quem a correspondência deve ser enviada 
un $18 \%$ sin observar cambios detrimentales en sus propiedades sensoriales El-Adawy (1997). La inclusión de harina de soya para mejorar el nivel proteico en panes a concentraciones del 4 al 8\% incrementaron la adsorción de agua, disminuyendo el tiempo de amasado, ya que el uso de niveles superiores aumentaron la pegajosidad e hicieron el pan más oscuro Yañez et al. (1982). Del mismo modo, la aplicación de concentrados de amaranto mejoró la funcionalidad de las masas, así como el valor biológico y la digestibilidad debido a la buena utilización del nitrógeno de amaranto, siendo una buena fuente de enriquecimiento para pan en dietas especiales De Luquez et al. (1997).

El lactosuero o suero de leche es la fase acuosa que se separa de la cuajada en el proceso de elaboración de quesos y contiene la mayor parte de las sustancias solubles, como lactosa, proteínas del suero, sales y algo de grasa Luquet (1993). Existen varios métodos para determinar la fracción proteica del lactosuero, donde el proceso de separación o concentración de las proteínas afectará definitivamente las propiedades funcionales de los concentrados. Este efecto puede incidir directa o indirectamente sobre su funcionalidad, esto es, que afecte ya sea la conformación o estructura de las proteínas o bien actúe indirectamente sobre la funcionalidad debido a variaciones en la composición Schimidt, Packard y Morris (1984). Los concentrados proteicos de lactosuero han sido un ingrediente común en la industria panificadora Güemes et al. (2008). Un proceso fácil para concentrar esta proteína es mediante la precipitación por calor, sobre todo sino se cuenta con equipos para secado por aspersión. La adición de esta proteína en los productos de panificación se debe principalmente porque en México el consumo per cápita es de $32 \mathrm{k}$ por año, en nuestro país panes como el bolillo, la telera y la concha, son los más demandados por la población, estas cifras están muy por debajo de naciones como los latinoamericanos y europeos. Existen países como Chile, Alemania y Francia con consumos per cápita de entre 75 y 95 k, Canainpa (2007).

El objetivo de este trabajo fue determinar el efecto de la incorporación de dos diferentes concentrados de lactosuero, uno comercial y otro obtenido por precipitación por calor, sobre las características químicas y de textura de las masas en pan dulce tipo "concha".

\section{Material y métodos}

\subsection{Preparación y almacenamiento de la masa}

Se prepararon lotes de $250 \mathrm{~g}$ de masa para cada tratamiento, mezclando $75 \%(\mathrm{p} / \mathrm{p})$ de harina de trigo Hoja de Plata (Molinos Elizondo, S.A. de C.V.), $2 \%(\mathrm{p} / \mathrm{p})$ de leche en polvo entera (Nestle, SA de CV, México), 2.25 (p/p) de levadura (Nevada S.A. de C.V.), sal, mantequilla y azúcar, estos ingredientes fueron utilizados en todas las formulaciones elaboradas. Para enriquecer las formulaciones utilizadas se adicionó proteínas de lactosuero en $0,10,15,20,25$ y $30 \%(\mathrm{p} / \mathrm{p})$ de un concentrado comercial LACTILAB (San Nicolás de los Garza, México) y de un precipitado por calor de acuerdo a lo reportado por Pruneda Olguin (2004), donde $10 \mathrm{~L}$ de lactosuero se calentaron a ebullición en una marmita hasta reducir su volumen a un tercio, obteniendo una pasta viscosa que se secó posteriormente en una estufa a $70{ }^{\circ} \mathrm{C}$ durante 12 horas. Se agregó $25 \mathrm{~mL}$ de agua y $25 \mathrm{~mL}$ de huevo, amasando en una batidora Kitchen Aid K45S de $1 \mathrm{~L}$ con el mezclador de gancho a velocidad media durante aproximadamente 5 minutos. Se agregó mantequilla LA GLORIA (Naucalpan, Estado de México) y se incorporó mezclando por 3 minutos más. Las masas fueron divididas en porciones de $83 \mathrm{~g}$ con forma de bollo, se fermentaron durante 20 minutos a $30^{\circ} \mathrm{C}$ y se hornearon a $180^{\circ} \mathrm{C}$ durante 20 minutos. Las masas de los diferentes tratamientos se almacenaron en bolsas de polietileno $\left(\mathrm{Ziploc}^{\mathrm{TM}}\right.$ ) a $4^{\circ} \mathrm{C}$ hasta su análisis, atemperadas a $60^{\circ} \mathrm{C}$, durante 10-15 minutos en porciones correspondientes a la cantidad necesaria para cada prueba.

\subsection{Análisis químico proximal}

Se realizó un análisis químico proximal de los panes con 10 y $15 \%$ del concentrado de proteínas de lactosuero utilizando los métodos oficiales recomendados por la AACC (1995), utilizando en las formulaciones el suero comercial y el precipitado por calor, determinando el contenido de proteína total por el método de Kjeldhal (método oficial 950.36), fibra cruda (método oficial 950.37), cenizas (método oficial 930.22), grasa (método oficial 935.38) y humedad (método oficial 935.36).

\subsection{Análisis de textura}

\section{Adhesividad de Hoseney de las masas}

Para determinar el efecto de la incorporación de los concentrados de lactosuero, se determinó la adhesividad de Hoseney de acuerdo a lo reportado por Chen y Hoseney (1995), utilizando el aditamento para adhesividad de masas SMS/Chen-Hoseney (Texture Technologies, New York, USA), adaptado a un equipo analizador de textura TA-HDi (Texture Technologies, New York, USA/Stable Microsystems, Surrey, UK). La masa de cada tratamiento fue colocada en el aditamento, llenando el mismo haciendo presión para obtener la muestra que se colocó en el aditamento Chen/Hoseney, dejándola reposar por un minuto. La muestra fue entonces comprimida a una velocidad constante de $1.7 \mathrm{~mm} / \mathrm{s}$, registrando la fuerza necesaria para retirar el vástago de la muestra.

\section{Análisis del perfil de textura}

La textura de las muestras de masa se determinó en el mismo equipo analizador de textura comprimiendo $20 \%$ de su altura original $25 \mathrm{~g}$ de masa con forma cilíndrica de $3 \mathrm{~cm}$ de alto. Las muestras se comprimieron dos veces consecutivamente con el vástago de 2" de diámetro a una velocidad de $1.7 \mathrm{~mm} / \mathrm{s}$ (LUQUET, 1993). La textura de los panes fue determinada en el mismo equipo comprimiendo dos veces las muestras en el centro $20 \%$ de su altura a una velocidad de $1.7 \mathrm{~mm} / \mathrm{s}$. De las curvas de fuerza-deformación se obtuvieron los parámetros del análisis del perfil de textura de acuerdo a lo reportado por Bourne (1978) y Texture Technologies (2003).

\subsection{Diseño experimental y análisis estadístico}

El efecto de incorporar dos tipos de concentrado de lactosuero en la fortificación de las masas y panes se determinó me- 
diante un análisis de varianza utilizando el paquete estadístico SAS v. 8.0 (SAS Institute, Cary, North Carolina). La diferencia entre medias se calculó utilizando la prueba de comparaciones múltiples de medias de Duncan.

El modelo estadístico propuesto fue (Ecuación 1):

$\mathrm{y}_{\mathrm{ij}}=\mu+\mathrm{t}_{\mathrm{j}}+\epsilon_{\mathrm{ij}}$

donde $y_{\mathrm{ij}}$ es el parámetro de la variable respuesta al i-ésimo tipo de concentrado de lactosuero al j-ésimo nivel de concentrado utilizado, $\mu$ es la media general, $t$ es la media de cada tratamiento considerando los porcentajes de inclusión de suero precipitado por calor $\mathrm{y} \in_{\mathrm{ij}}$ representa el error experimental.

\section{Resultados y discusión}

\subsection{Análisis químico proximal de panes fortificados con lactosuero.}

En la Tabla 1 se observa los resultados del análisis químico próximal del pan sin fortificar y de los panes fortificados con 10 y $15 \%$ de los concentrados de lactosuero. La humedad fue similar en las muestras, sólo un poco menor en los panes con $10 \%$ de lactosuero precipitado por calor. Como era de esperarse, el contenido de proteína fue mayor al aumentar en porcentaje de lactosuero concentrado. La muestra comercial presentó un incremento en el precipitado por calor debido probablemente al mayor contenido de proteína del primero, pues el tratamiento térmico puede desnaturalizar parte de la proteína durante su concentración Pruneda Olguin (2004). Sin embargo, el aumento en el porcentaje de proteína respecto al control fue significativo. Las muestras con lactosuero concentrado por calor tuvieron valores altos en el porcentaje de grasa ya que éste no fue descremado antes de precipitarlo, práctica común a nivel industrial.
Del mismo modo, un mayor porcentaje de lactosuero aumentó el porcentaje de cenizas debido a los minerales presentes en los concentrados de lactosuero.

\subsection{Textura}

\section{Adhesividad Hoseney de las masas}

La incorporación de lactosuero modificó la adhesividad de las masas, pero no se encontró diferencia significativa entre ambos tipos de concentrados de lactosuero. La masa sin suero mostró mayor trabajo de adhesión en comparación con el resto de los tratamientos, donde el incorporar un 10\% resultó en los menores valores, pero porcentajes mayores de suero tuvieron valores intermedios sin diferencia significativa entre ellos, debido al traslape de medias. En la firmeza de adhesión, a pesar de que el 10\% de suero resultó en la menor área de adhesión, ésta correspondió a los valores más altos de firmeza en comparación con el control y el resto de los tratamientos, los cuales a su vez no fueron significativamente diferentes entre ellos (Tabla 2). Las formas de las curvas obtenidas en el formato fuerza-distancia se trata de un material más adhesivo que cohesivo según la clasificación dada por Texture Technologies (2003). Esto quiere decir que el incorporar un $10 \%$ de cualquier suero mejora la firmeza de adhesión de las masas, pero no así la energía necesaria para manejarla, lo cual implica menor adhesión a la superficie de los equipos facilitando su maleabilidad este aspecto reduce costos en los procesos de producción además de no afectar las reacciones de caramelización durante el horneado y las propiedades de color de este tipo de pan, en el cual es muy usual utilizar colorantes de color amarillo para ser atractivos de forma visual al consumidor, además de mejorar las propiedades sensoriales del sabor. Porcentajes arriba del $15 \%$ no mejoran estas propiedades las detrimenta. Al respecto, Totosaus (2004) reportó que

Tabla 1. Análisis químico próximal de los panes fortificados con lactosuero comercial y lactosuero precipitado por calor.

\begin{tabular}{|c|c|c|c|c|c|}
\hline & \multirow[b]{2}{*}{$0 \%$} & \multicolumn{2}{|c|}{ Suero comercial } & \multicolumn{2}{|c|}{ Suero precipitado por calor } \\
\hline & & $10 \%$ & $15 \%$ & $10 \%$ & $15 \%$ \\
\hline Humedad & $12.8 \pm 0.03^{\mathrm{a}}$ & $13.7 \pm 0.02^{\mathrm{a}}$ & $11.6 \pm 0.02^{\mathrm{a}, \mathrm{b}}$ & $9.3 \pm 0.21^{\mathrm{b}}$ & $13.1 \pm 0.01^{\circ}$ \\
\hline Proteína & $17.2 \pm 0.01^{\mathrm{d}}$ & $19.8 \pm 0.01^{\mathrm{c}}$ & $22.9 \pm 0.03^{\mathrm{a}}$ & $19.8 \pm 0.02^{\mathrm{c}}$ & $20.5 \pm 0.03$ \\
\hline Grasa & $7.01 \pm 0.02^{c}$ & $7.29 \pm 0.04^{b}$ & $7.37 \pm 0.01^{\mathrm{a}}$ & $7.26 \pm 0.05^{\mathrm{b}}$ & $7.35 \pm 0.06^{\circ}$ \\
\hline Ceniza & $0.01 \pm 0.04^{\mathrm{d}}$ & $0.08 \pm 0.03^{\mathrm{c}}$ & $0.09 \pm 0.04^{\mathrm{a}}$ & $0.08 \pm 0.01^{\mathrm{c}}$ & $0.09 \pm 0.01^{\mathrm{b}}$ \\
\hline
\end{tabular}

${ }_{\mathrm{a}, \mathrm{b}}$ Medias con la misma letra en la misma columna no son significativamente diferentes $(\mathrm{p}>0.05)$.

Tabla 2. Adhesividad de las masas de harina de trigo fortificadas con lactosuero comercial y lactosuero precipitado por calor.

\begin{tabular}{|c|c|c|c|c|}
\hline & \multicolumn{2}{|c|}{ Suero comercial } & \multicolumn{2}{|c|}{ Suero precipitado por calor } \\
\hline & Trabajo de adhesión (N/s) & Firmeza $(\mathrm{N})$ & Trabajo de adhesión (N/s) & Firmeza $(\mathrm{N})$ \\
\hline $0 \%$ & $-0.1625 \pm 0.012^{\mathrm{A}, \mathrm{a}}$ & $-0.4075 \pm 0.005^{\mathrm{B}, \mathrm{b}}$ & $-0.1625 \pm 0.012^{\mathrm{A}, \mathrm{a}}$ & $-0.4075 \pm 0.005^{\mathrm{B}, \mathrm{b}}$ \\
\hline $10 \%$ & $-0.2625 \pm 0.040^{\mathrm{B}, \mathrm{c}}$ & $-0.3950 \pm 0.006^{\mathrm{A}, \mathrm{a}}$ & $-0.1700 \pm 0.010^{\mathrm{B}, \mathrm{c}}$ & $-0.4067 \pm 0.005^{\mathrm{B}, \mathrm{a}}$ \\
\hline $15 \%$ & $-0.2125 \pm 0.032^{\mathrm{B}, \mathrm{bc}}$ & $-0.4000 \pm 0.001^{\mathrm{A}, \mathrm{ab}}$ & $-0.1867 \pm 0.005^{\mathrm{B}, \mathrm{bc}}$ & $-0.4067 \pm 0.005^{\mathrm{B}, \mathrm{ab}}$ \\
\hline $20 \%$ & $-0.1667 \pm 0.015^{\mathrm{B}, \mathrm{abc}}$ & $-0.4000 \pm 0.001^{\mathrm{A}, \mathrm{ab}}$ & $-0.2200 \pm 0.036^{\mathrm{B}, \mathrm{abc}}$ & $-0.4033 \pm 0.006^{\mathrm{B}, \mathrm{ab}}$ \\
\hline $25 \%$ & $-0.1767 \pm 0.015^{\mathrm{B}, \mathrm{ab}}$ & $-0.4000 \pm 0.001^{\mathrm{A}, \mathrm{ab}}$ & $-0.1933 \pm 0.015^{\mathrm{B}, \mathrm{ab}}$ & $-0.4067 \pm 0.005^{\mathrm{B}, \mathrm{ab}}$ \\
\hline $30 \%$ & $-0.1650 \pm 0.021^{\mathrm{B}, \mathrm{ab}}$ & $-0.4000 \pm 0.001^{\mathrm{A}, \mathrm{ab}}$ & $-0.1967 \pm 0.041^{\mathrm{B}, \mathrm{ab}}$ & $-0.4067 \pm 0.005^{\mathrm{B}, \mathrm{ab}}$ \\
\hline
\end{tabular}

$\mathrm{A}, \mathrm{B}$ Medias con la misma letra en el mismo renglón no son significativamente diferentes; ( $\mathrm{p}>0.05)$ por tipo de suero; $\mathrm{y}^{\mathrm{a}, \mathrm{b}}$ medias con la misma letra en el misma columna no son significativamente diferentes $(\mathrm{p}>0.05)$ por porcentaje de suero. 
las proteínas de lactosuero precipitadas por calor tuvieron una mayor capacidad de retener agua en batidos cárnicos, debido probablemente a la relación que existe entre el tratamiento térmico y la solubilidad de la proteína al ser concentradas. Esto puede explicar el comportamiento que tienen las proteínas de lactosuero precipitadas por calor provocando una mayor adhesividad del material al aumentar el contenido de éste. Las proteínas de lactosuero al precipitarse por calor tienen más facilidad de coagular debido a la desnaturalización que sufren al momento de ser tratadas con calor Belitz y Grosch (2002), Morr (1989). Sin embargo, a pesar del tratamiento térmico durante la precipitación, las proteínas del lactosuero mantuvieron su funcionalidad al no disminuir las propiedades de las masas, lo cual probablemente indique una buena interacción entre éstas y las proteínas y demás componentes de las masas. Análisis del Perfil de Textura de las masas fortificadas. En la Tabla 2 también se observa que los valores para el trabajo de adhesión aumenta en el 10\% del suero comercial y luego disminuye al aumentar las concentraciones, al respecto Güemes et al. (2008) reportan que estas diferencias que se presentan es probable a los altos contenidos de proteínas y de carbohidratos que tienen las formulaciones de estos productos, ya que se les adiciona huevo y leche, que al conjuntarse con las proteínas de lactosuero provocan un aumento de la adhesión, la disminución de la adhesión lograría estar en función de: 1) La materia usada para este pan ya que puede cambiar la acción de las levaduras; 2) el ponchado y boleado de la masa, se considera como una energía mecánica adicional, repercutiendo en el desarrollo de la masa; y 3) el tiempo de fermentación utilizado, es importante considerar la presencia de las proteínas de lactosuero que podrían estar afectando la formación de la red del gluten.

En el análisis del perfil de textura de las masas se encontró un efecto significativo $(p<0.05)$ en la dureza y cohesividad, pero no así en la resilencia y elasticidad ( $p>0.05)$. La firmeza de la masa fue mayor para los ejemplos con suero comercial, pero menos cohesivas que las muestras con suero precipitado con calor. Para el porcentaje de suero se encontró que mayores porcentajes ( 25 y $30 \%$ ) hicieron a las masas más duras, pero sin efecto en la cohesividad ni en los otros parámetros estudiados (Tabla 3). La concentración del 5\% en el Suero Comercial o Suero Precipitado por Calor provoca un aumento en la cohesividad de la pasta, pero tiene repercusiones en la firmeza y la consistencia de éstas Gélinas et al. (1995). Totosaus (2004) reportó que la incorporación de estos concentrados de lactosuero en batidos cárnicos formaron un gel más compacto, probablemente a la interacción con otras proteínas, requiriendo de más fuerza para ser deformadas. En el caso de las masas fortificadas, esto podría deberse a que la proteína del suero tiene un efecto sobre la estructura de la masa, ya que al ser hidratada con el resto de los ingredientes afecta su dureza, pero sin tener ningún tipo de interacción en la masa pues no afectó los parámetros relativos a la integridad de la masa, como son cohesividad y resiliencia ni a la elasticidad. Estos datos concuerdan con lo reportado por Ramirez (2002), quien menciona que las masas que presentan estas características se consideran un material más adhesivo que cohesivo. La proteína de lactosuero desnaturalizada puede afectar la viscoelasticidad y la calidad de las masas, ocasionando una disminución en la absorción de agua e interfiriendo con la formación de la red del gluten, esto podría explicar en cierta forma el porque se ven afectadas las masas en su cohesividad y firmeza Ashworth y Krueger (1951), Erdogdu-Arnoczky, Czuchajowska y Pomeranz (1996). Los resultados obtenidos de las gráficas muestran unas curvas que en general pueden decir que presentan un comportamiento de material suave (los valores de fuerza máxima (firmeza) reportados en general son bajos con respecto a otros reportados por Ramirez (2002)), cohesivo (pues la diferencia en el tamaño de las áreas del primer y segundo ciclo de compresión no es grande, de hecho los valores de cohesividad están muy cercanos a la unidad en la mayoría de los casos, lo que marca un valor de área similar en ambos picos de compresión) y con características adhesivas lo cual denota presencia de un área negativa de magnitud significativa entre el primer y segundo ciclo de compresión de la curva Güemes et al. (2005).

\section{Análisis del perfil de textura en panes fortificados}

Las Tablas 4 y 5 muestran los valores obtenidos en el análisis del perfil de textura de los panes fortificados con 10 y $15 \%$ de lactosuero, donde la incorporación del lactosuero concentrado disminuyó la firmeza, pero sin diferencia significativa $(p>0.05)$ respecto al tipo de lactosuero. La firmeza del pan fortificado muestra una disminución en comparación al testigo, demostrando que las proteínas de suero lácteo mejoran las propiedades de textura del alimento en el que son incorporadas, en estos resultados también se presenta que la adhesividad no tuvo efecto por la adición de los concentrados de lactosuero Güemes et al. (2005). Esteller, Lira y Silva Lannes (2004) mencionan que durante el proceso de mezclado, los ingredientes (azúcar, sal, levaduras, etc) no se pueden incorporar de una forma uniforme al mezclarlos con agua, aunque en el proceso

Tabla 3. Análisis del perfil de textura para las masas de harina de trigo fortificadas con lactosuero comercial y lactosuero precipitado por calor.

\begin{tabular}{|c|c|c|c|c|c|c|c|c|}
\hline & \multicolumn{4}{|c|}{ Suero comercial } & \multicolumn{4}{|c|}{ Suero precipitado por calor } \\
\hline & Firmeza $(\mathrm{N})$ & Cohesividad & Resilencia & Resorteo & Firmeza (N) & Cohesividad & Resilencia & Elasticidad \\
\hline $10 \%$ & $3.14 \pm 0.40^{\mathrm{A}, \mathrm{b}}$ & $0.6853 \pm 0.04^{\mathrm{Baa}}$ & $0.2110 \pm 0.04^{\mathrm{A}, \mathrm{a}}$ & $1.004 \pm 0.01^{\mathrm{A}, \mathrm{a}}$ & $0.46 \pm 0.12^{\mathrm{B}, \mathrm{b}}$ & $0.6788 \pm 0.10^{\mathrm{A}, \mathrm{a}}$ & $0.1773 \pm 0.02^{\mathrm{A}, \mathrm{a}}$ & $0.9995 \pm 0.01^{\mathrm{A}, \mathrm{a}}$ \\
\hline $15 \%$ & $4.16 \pm 0.41^{\mathrm{A}, \mathrm{ab}}$ & $0.6446 \pm 0.03^{\mathrm{B}, \mathrm{a}}$ & $0.2248 \pm 0.02^{\mathrm{A}, \mathrm{a}}$ & $1.001 \pm 0.01^{\mathrm{A}, \mathrm{a}}$ & $1.24 \pm 0.45^{\mathrm{B}, \mathrm{ab}}$ & $0.7686 \pm 0.03^{\mathrm{A}, \mathrm{a}}$ & $0.2029 \pm 0.01^{\mathrm{A}, \mathrm{a}}$ & $0.9963 \pm 0.01^{\mathrm{A}, \mathrm{a}}$ \\
\hline $20 \%$ & $3.21 \pm 0.23^{\mathrm{A}, \mathrm{ab}}$ & $0.6318 \pm 0.02^{\mathrm{B}, \mathrm{a}}$ & $0.1759 \pm 0.02^{\mathrm{A}, \mathrm{a}}$ & $1.000 \pm 0.00^{\mathrm{A}, \mathrm{a}}$ & $2.02 \pm 1.56^{\mathrm{B}, \mathrm{ab}}$ & $0.7660 \pm 0.05^{\mathrm{A}, \mathrm{a}}$ & $0.2392 \pm 0.04^{\mathrm{A}, \mathrm{a}}$ & $1.000 \pm 0.01^{\mathrm{A}, \mathrm{a}}$ \\
\hline $25 \%$ & $4.22 \pm 1.61^{\mathrm{A}, \mathrm{a}}$ & $0.6287 \pm 0.02^{\mathrm{B}, \mathrm{a}}$ & $0.1885 \pm 0.02^{\mathrm{A}, \mathrm{a}}$ & $0.9965 \pm 0.01^{\mathrm{A}, \mathrm{a}}$ & $1.18 \pm 0.26^{\mathrm{B}, \mathrm{a}}$ & $0.8338 \pm 0.02^{\mathrm{A}, \mathrm{a}}$ & $0.1982 \pm 0.01^{\mathrm{A}, \mathrm{a}}$ & $0.9960 \pm 0.00^{\mathrm{A}, \mathrm{a}}$ \\
\hline $30 \%$ & $4.01 \pm 1.05^{\mathrm{A}, \mathrm{a}}$ & $0.6743 \pm 0.00^{\mathrm{B}, \mathrm{a}}$ & $0.2055 \pm 0.03^{\mathrm{A}, \mathrm{a}}$ & $1.000 \pm 0.01^{\mathrm{A}, \mathrm{a}}$ & $1.96 \pm 0.33^{\mathrm{Ba}}$ & $0.6911 \pm 0.07^{\mathrm{A}, \mathrm{a}}$ & $0.2199 \pm 0.03^{\mathrm{A}, \mathrm{a}}$ & $0.9968 \pm 0.01^{\mathrm{A}, \mathrm{a}}$ \\
\hline
\end{tabular}

${ }_{\mathrm{A}, \mathrm{B}}$ Medias con la misma letra en el mismo renglón no son significativamente diferentes ( $\left.\mathrm{p}>0.05\right)$ por tipo de suero; $\mathrm{y}^{\mathrm{a}, \mathrm{b}}$ medias con la misma letra en el misma columna no son significativamente diferentes $(\mathrm{p}>0.05)$ por porcentaje de suero. 
se controle el tiempo de mezclado. También mencionan acerca del proceso de fermentación en el cual el agua, los compuestos volátiles y el $\mathrm{CO}_{2}$ se difunden en una solución formada por almidones y proteínas, esto da como resultado celdas de gas de varios tamaños. Éstas en la miga pueden causar variaciones en la firmeza y en otros parámetros de textura del pan. Las muestras sin lactosuero fueron del mismo modo más fracturables, sobre todo las que contenían lactosuero precipitado por calor (Tabla 4), esto podría relacionarse con el contenido de humedad que a menor contenido de ésta el pan pierde suavidad y por lo tanto se hace más fracturable. También es importante considerar el alto contenido de azúcares, grasa y proteína que estan presentes por la presencia del lactosuero, lo cual puede modificar la fracturabilidad del pan. Esteller, Amaral y Lannes (2004) reportan que los panes que tienen más contenido de azúcar y grasa pierden cohesividad, caso contrario a lo que se observa en la Tabla 5 con respecto a la cohesividad de los panes ya que no hubo efecto en la cohesividad y la elasticidad de los panes al incorporar los concentrados de lactosuero, pero sí sobre la resiliencia. Solamente en la resiliencia la diferencia por el tipo de lactosuero fue significativa, ya que las muestras con el concentrado por calor fueron más resilientes (Tabla 5).

Kenny, Dybing y Smith (2000) reportaron que las proteínas del lactosuero pueden variar debido a su composición y a la desnaturalización durante su procesamiento, ya que esta desnaturalización hace que las proteínas sean más solubles, mejorando su solubilidad, por lo que pueden emulsificar y formar geles al calentarse, aunque la dureza disminuyó conforme aumentó la adición del lactosuero. La incorporación de proteínas de lactosuero modificó el aroma y firmeza de panes fortificados Gélinas et al. (1995). El suero precipitado por calor tuvo características más aceptables de textura, ya que sólo presentó valores menores de cohesividad en comparación con el lactosuero comercial. El color de los panes adicionados con los concentrados de lactosuero aumentaban su coloración amarilla.

\section{Conclusiones}

Se encontró un efecto significativo del tipo y concentración del suero precipitado por calor analizado en la adhesividad de las masas. La incorporación del 10\% de cualquier tipo de suero mejora la fuerza de adhesión de las masas. La adhesividad de las masas se ve afectada por la presencia de proteínas precipitadas por calor las cuales se desnaturalizan al momento de concentrarse. Porcentajes arriba del 15\%, no mejoran estas propiedades. Porcentajes mayores del 25 al 30\% dan la característica de dureza a las masas, pero sin efecto en la cohesividad y en otros parámetros obtenidos del análisis del perfil de textura. Respecto a la textura de los panes, el suero precipitado por calor tuvo características aceptables de APT en comparación con el suero comercial. En cuanto al contenido de proteína de los panes adicionados con suero precipitado por calor tuvieron un ligero incremento con respecto al pan testigo.

\section{Referencias}

American Association of Cereal Chemistry. Approved Methods of American Association of Cereal Chemist. St. Paul, 1995.

ASHWORTH, U. S.; KRUEGER, G. J. Chemical factors affecting the baking quality of non-fat milk solids. IV. Minimum heat treatment for maximum loaf volume. Cereal Chemistry, v. 28, n. 2, p. 145-152, 1951.

BELITZ, L.; GROSCH, W. Química de los Alimentos. Zaragoza: Acribia, 2002. p. 125.

BOURNE, M. C. Texture profile analysis. Food Technology, v. 32, n. 7, p. 62-66, 72, 1978.

CÁMARA Nacional de la Industria Panificadora y Similares de Mexico - CANAINPA. 2007. Disponível em:http://www.canainpa. com.mx/.

CHEN, W. Z.; HOSENEY, R. C. Development of an objective method for dough stickiness. Lebensmittel-Wissenschaft und-Technologie, v. 28 , n. 5 , p. $467-473,1995$.

Tabla 4. Dureza y fracturabilidad en el análisis del perfil de textura para los panes fortificados con lactosuero comercial y lactosuero precipitado por calor.

\begin{tabular}{|c|c|c|c|c|}
\hline & \multicolumn{2}{|c|}{ Suero comercial } & \multicolumn{2}{|c|}{ Suero precipitado por calor } \\
\hline & Firmeza $(\mathrm{N})$ & Fracturabilidad & Firmeza $(\mathrm{N})$ & Fracturabilidad \\
\hline $0 \%$ & $24.37 \pm 8.7^{\mathrm{A}, \mathrm{a}}$ & $7.99 \pm 1.83^{\mathrm{A}, \mathrm{b}}$ & $24.37 \pm 8.7^{\mathrm{A}, \mathrm{a}}$ & $7.99 \pm 1.83^{\mathrm{B}, \mathrm{b}}$ \\
\hline $10 \%$ & $14.15 \pm 4.47^{\mathrm{B}, \mathrm{b}}$ & $6.26 \pm 1.59^{\mathrm{B}, \mathrm{a}}$ & $13.97 \pm 2.07^{\mathrm{B}, \mathrm{b}}$ & $13.34 \pm 1.67^{\mathrm{A}, \mathrm{a}}$ \\
\hline $15 \%$ & $9.81 \pm 1.27^{\mathrm{B}, \mathrm{b}}$ & $4.28 \pm 1.72^{\mathrm{B}, \mathrm{a}}$ & $15.14 \pm 1.98^{\mathrm{B}, \mathrm{b}}$ & $24.05 \pm 1.89^{\mathrm{A}, \mathrm{a}}$ \\
\hline
\end{tabular}

$\mathrm{A}, \mathrm{B}$ Medias con la misma letra en el mismo renglón no son significativamente diferentes $(\mathrm{p}>0.05)$ por tipo de suero; $\mathrm{y}$ a,bmedias con la misma letra en el misma columna no son significativamente diferentes $(\mathrm{p}>0.05)$ por porcentaje de suero.

Tabla 5. Cohesividad, resiliencia y elasticidad en el análisis del perfil de textura para los panes fortificados con lactosuero comercial y lactosuero precipitado por calor.

\begin{tabular}{|c|c|c|c|c|c|c|}
\hline & \multicolumn{3}{|c|}{ Suero comercial } & \multicolumn{3}{|c|}{ Suero precipitado por calor } \\
\hline & Cohesividad & Resilencia & Elasticidad & Cohesividad & Resilencia & Elasticidad \\
\hline $0 \%$ & $0.2712 \pm 0.02^{\mathrm{A}, \mathrm{a}}$ & $0.0964 \pm 0.01^{\mathrm{B}, \mathrm{b}}$ & $0.9986 \pm 0.00^{\mathrm{A}, \mathrm{a}}$ & $0.2712 \pm 0.02^{\mathrm{A}, \mathrm{a}}$ & $0.0964 \pm 0.01^{\mathrm{B}, \mathrm{b}}$ & $0.9986 \pm 0.00^{\mathrm{A}, \mathrm{a}}$ \\
\hline $10 \%$ & $0.2430 \pm 0.03^{\mathrm{AB}, \mathrm{a}}$ & $0.0748 \pm 0.01^{\mathrm{Baa}}$ & $0.9989 \pm 0.00^{\mathrm{A}, \mathrm{a}}$ & $0.2058 \pm 0.01^{\mathrm{Baa}}$ & $0.2167 \pm 0.21^{\mathrm{A}, \mathrm{a}}$ & $1.1151 \pm 0.16^{\mathrm{A}, \mathrm{a}}$ \\
\hline $15 \%$ & $0.2489 \pm 0.04^{\mathrm{AB}, \mathrm{a}}$ & $0.080 \pm 0.02^{\mathrm{B}, \mathrm{b}}$ & $1.0005 \pm 0.00^{\mathrm{A}, \mathrm{a}}$ & $0.2436 \pm 0.02^{\mathrm{Baa}}$ & $0.0738 \pm 0.02^{\mathrm{A}, \mathrm{b}}$ & $0.9949 \pm 0.01^{\mathrm{A}, \mathrm{a}}$ \\
\hline
\end{tabular}

${ }_{\mathrm{A}, \mathrm{B}}$ Medias con la misma letra en el mismo renglón no son significativamente diferentes ( $\mathrm{p}>0.05$ ) por tipo de suero; $\mathrm{y}^{\mathrm{a}, \mathrm{b}}$ medias con la misma letra en la misma columna no son significativamente diferentes $(\mathrm{p}>0.05)$ por porcentaje de suero. 
DE LUQUEZ, N.; FERNANDEZ, S.; DE ARELLANO, M. L.; DE MUCCIARELLI, S. I. Concentrado proteico de Amaranthus mantegazzianus. Caracterización físico, química y biológica. Archivos Latinoamericanos de Nutrición, v. 47, n. 4, p. 359-361, 1997.

EL-ADAWY, T. A. Effect of sesame seed protein supplementation on the nutritional, physical, chemical and sensory properties of wheat flour bread. Food Chemistry, v. 59, n. 1, p. 7-14, 1997.

ERDOGDU-ARNOCZKY, N.; CZUCHAJOWSKA, Z.; POMERANZ, Y. Functionality of whey and casein in fermentation and bread baking by fixed and optimized procedures. Cereal Chemistry, v. 73, n. 3, p. 309-316, 1996.

ESTELLER, M. S., AMARAL, R. L., LANNES, S. C. S. Effect of sugar and fat replacers on the texture of baked goods. Journal of Texture Studies, v. 35, n. 4, p. 383-393, 2004.

GÉLINAS, P. et al. Fermented dairy ingredients for bread: effects on dough rheology and bread characteristics. Cereal Chemistry, v. 72, n. 2, p. 151-154, 1995.

GÜEMES-VERA, N.; ARCINIEGA-RUIZ ESPARZA, O.; DÁVILAORTIZ, G. Structural analysis of the Lupinus mutabilis seed, its flour, concentrate, and isolate as well as their behavior when mixed with wheat flour. Lebensmittel-Wissenschaft und-Technologie, v. 37, n. 3, p. 283-290, 2004.

GÜEMES-VERA, N. et al. Análisis de perfil de textura em masas y panes dulces de harina trigo fortificadas com lactosuero. In: CONGRESO NACIONAL DE CIÊNCIA DE LOS ALIMENTOS Y FORO DE CIÊNCIA Y TECNOLOGIA DE ALIMENTOS, 7 y 3, Guanajuato, Gto. Disponível em:www.uanl.mx/publicaciones/ respyn/especiales/2005/ee-13-2005/documentos/CNA21.pdf.

GÜEMES-VERA, N. et al. Effective detoxification and decoloration of Lupinus mutabilis seed derivatives, and effect of these derivatives on bread quality and acceptance. Journal of the Science of Food and Agriculture, v. 88, n. 3, p. 1135-1143, 2008.
KENNY, S. et al. Incorporation of dairy ingredients into wheat bread: effects on dough rheology and bread quality. European Food Research Technology, v. 210, n. 6, p. 391-396, 2000.

LUQUET, F. M. Leche y Productos Lácteos. Zaragoza: Acribia, 1993. p. 278-317.

MODLER, H. W. Milk processing. Nakai, S.; Modler, H. W. (Eds.). Food Proteins. New York: Wiley-VCH, 2000. p. 1-88.

MORR, C. V. Whey proteins. Manufacture. In: Fox, P. F. (Ed.). Developments in Dairy Chemistry. London: Elsevier Applied Science, 1989.

PRUNEDA OLGUÍN, E. Funcionalidad de proteínas de lactosuero precipitadas por calor en un sistema cárnico. México, 2004. Tesis (Licenciatura Ingeniería Agroindustrial) - UAEH.

RAMÍREZ, O. M. E. Modelamiento matemático del comportamiento viscoelásticos dinámico y textural de masas para elaborar pizza. México, 2002. Tesis (Maestría en Ciencias con especialidad en Alimentos), Escuela Nacional de Ciencias Biológicas del Instituto Politécnico Nacional.

SCHIMIDT, R. H.; PACKARD, V. S.; MORRIS, H. A. Effect of processing on whey protein functionality. Journal of Dairy Science, v. 67, n. 3, p. 2723-2733, 1984.

TAHA, F. S.; ATTIA, M.; SHEHATA, N. A. Protein enrichment of bread: I. Chemical and sensoric evaluation. ZErnährungswiss., v. 21, n. 1, p. 77-82, 1982.

TEXTURE TECHNOLOGIES. Texture Technologies, 2003. Textural profile analysis explained \& annotated. Disponível em:http://www. texturetechnologies.com/texture_profile_analysis.html. Acesso em: Nov 2004.

TOTOSAUS, A. Functionality of glicosilated heart surimi and heatprecipitated whey proteins in meat batters. Journal Muscle Foods., v. 15 , n. 5 , p. $256-268,2004$.

YANEZ, E. et al. Enriquecimiento de pan con harina de soya. Archivos Latinoamericanos de Nutrición., v. 32, n. 2, p. 417-428, 1982. 